MT-DP - 2019/6

\title{
The risk-based core for cooperative games with uncertainty
}

LÁSZLÓ Á. KÓCZY 


$$
\begin{aligned}
& \text { Discussion papers } \\
& \text { MT-DP - 2019/6 }
\end{aligned}
$$

Institute of Economics, Centre for Economic and Regional Studies, Hungarian Academy of Sciences

KTI/IE Discussion Papers are circulated to promote discussion and provoque comments.

Any references to discussion papers should clearly state that the paper is preliminary. Materials published in this series may subject to further publication.

The risk-based core for cooperative games with uncertainty

Author:

\author{
László Á. Kóczy \\ senior research fellow \\ 'Momentum' Game Theory Research Group \\ Centre for Economic and Regional Studies \\ Hungarian Academy of Sciences \\ and \\ Department of Finance \\ Faculty of Economic and Social Sciences \\ Budapest University of Technology and \\ Economics \\ koczy.laszlo@krtk.mta.hu
}

February 2019 


\title{
The risk-based core for cooperative games with uncertainty
}

\author{
László Á. Kóczy
}

\section{Abstract}

In coalitional games with uncertain payoffs, a deviating coalition can only form expectations regarding its post-deviation payoff. Classical approaches address the problem from the side of conservatism, expecting the worst, or by explicit assumptions of the emerging state of the world. We borrow the idea of risk from the finance literature and compare the payoff of staying with the original outcome with the risk of deviating. Employing this idea to the core leads to a new concept that we call the risk-based core. We introduce this concept and discuss its properties. We find an inclusion relation between cores of games with increasingly conservative players. The model is also suitable to study cooperative games in partition function form where the value of a coalition depends on the entire partition. For the cores of such games our main result yields many of the familiar inclusion relations as corollaries, while the inclusion of the optimistic core in the optimistic recursive core turns out to be non-robust.

Keywords: Cooperative game theory; Core; Expectation formation rules; Risk, Risk measures; Partition function form games

JEL codes: C71; D82; G32 


\title{
A bizonytalan kifizetésű kooperatív játékok kockázati magja
}

\author{
Kóczy Á. László
}

Összefoglaló

A bizonytalan kifizetésű kooperatív játékokban egy elhajló koalíciónak legfeljebb várakozásai lehetnek a kifizetését illetően. A klasszikus megközelítés a problémát konzervativizmussal - a legrosszabbra számítva - kezeli, vagy explicit feltételezéseket tesz a várható világállapotról. Mi a pénzügyes irodalomból vesszük kölcsön a kockázat fogalmát és a koalíció jelenlegi értékét az elhajlás kockázatával vetjük össze. Az elképzelést a magra alkalmazva kapjuk az általunk kockázati magnak nevezett fogalmat. Bevezetjük a koncepciót és megvizsgáljuk a tulajdonságait. Az egyre konzervatívabb játékosokkal képzett kockázati magok halmazai között bennfoglalási kapcsolatot figyelünk meg. A modell alkalmas partíciós függvényalakú kooperatív játékok elemzésére is, amelyekben a koalíció az egész partíció értékétől függ. E játékok különböző várakozási szabályokkal számolt magjára a tétel következményeként megkapjuk a szokásos bennfoglalási kapcsolatok jelentôs részét, ugyanakkor az optimista és az optimista rekurzív mag viszonya nem robusztus.

Tárgyszavak: kooperatív játékelmélet, mag, várakozási szabály, kockázat, kockázati mérték, partíciós függvényalakú játék

JEL: C71, D82, G32 


\title{
The risk-based core for cooperative games with uncertainty
}

\author{
László Á. Kóczy*
}

\begin{abstract}
In coalitional games with uncertain payoffs, a deviating coalition can only form expectations regarding its post-deviation payoff. Classical approaches address the problem from the side of conservatism, expecting the worst, or by explicit assumptions of the emerging state of the world. We borrow the idea of risk from the finance literature and compare the payoff of staying with the original outcome with the risk of deviating. Employing this idea to the core leads to a new concept that we call the risk-based core. We introduce this concept and discuss its properties. We find an inclusion relation between cores of games with increasingly conservative players. The model is also suitable to study cooperative games in partition function form where the value of a coalition depends on the entire partition. For the cores of such games our main result yields many of the familiar inclusion relations as corollaries, while the inclusion of the optimistic core in the optimistic recursive core turns out to be non-robust.
\end{abstract}

KEywords. Cooperative game theory; Core; Expectation formation rules; Risk, Risk measures; Partition function form games

JEL CODES. C71; D82; G32

\section{Introduction}

Cooperative game theory is built on models where the value of each coalition is known in advance. In many real life situations, however, we may not have a complete understanding of all circumstances and different states of the world

\footnotetext{
*'Momentum' Game Theory Research Group, Centre for Economic and Regional Sciences, Hungarian Academy of Sciences, Tóth Kálmán u. 4, H-1097 Budapest and Department of Finance, Faculty of Economic and Social Sciences, Budapest University of Technology and Economics, Magyar tudósok körútja 2, H-1117 Budapest. Email: koczy@krtk.mta.hu
} 
may yield substantially different payoffs. One can think of portfolios of assets, for example. The value of each asset is a random variable realising different values in different states of the world. The value of coalitions, that is, portfolios of assets may simply be calculated additively, but one may consider diversification effects leading the a superadditive value function or liquidity constraints corresponding to subadditivity - or any combinations thereof. In TU games the uncertainty is seen as exogenous, originating from mechanisms not modelled within the game, but we assume that the change is triggered by the players. In NTU games or games in partition function form this is more obvious as the play of other players may influence a coalition's payoffs. Practical applications of games with random payoffs include linear production games with uncertain resource bundles, trader's cooperation in financial markets, sequencing problems with stochastic processing times (Suijs et al., 1999) and non-life insurance (Suijs et al., 1998).

Along with the cooperative games tradition we assume that a particular allocation is proposed and we are interested in proposals that are not subject to deviations by coalitions of the players. This idea generalises the core (Shapley, $1955)$ to cooperative games with random payoffs.

Uncertainty about a coalition's payoff appears in different streams of the literature. First Charnes and Granot (1973, 1976); Granot (1977) introduced chance-constrained games where the coalitional payoffs are not deterministic, but random variables with known distributions. An important element of this model is the separation of bargaining about the payoffs and their realisation. Coalitions may make some promises to their members on the basis of the payoff distributions, but these promises should be such that the payments can be made once the payoffs are realised. In this sense the concepts discussed are prior solutions. One of the problems of this approach is the assumption of risk neutrality. Suijs et al. (1999) considers a model where coalitions have actions leading to different random payoffs and the players have a preferencerelation to compare random payoffs with each other. Suijs et al. (1999) focus on the particular setting where coalitional agreements specify the allocation of the expected payoff and a separate allocation of the difference between the expected and realised payoffs. Timmer et al. (2005) use a similar formulation, but the different realisations of the payoff are not linked to actions by the coalition. Bossert et al. (2005) look at games where the uncertainty is about the choice between two TU games and correspondingly the uncertainty about the value of a coalition corresponds to the uncertainty about the game played. More recently Habis and Herings (2011); Habis and Csercsik (2015) introduces uncertainty in 
the dynamic model of initiated by Koutsougeras (1998) now characterised by the weak- and strong sequential cores (Predtetchinski et al., 2002; Predtetchinski, 2007; Habis and Herings, 2010). At last, Kóczy (2002) and Konishi and Ray (2003) consider dynamic coalitional games with foresighted players. In such games a coalitional deviation triggers a sequence of further deviations: as often multiple deviations are possible there is uncertainty about possible paths with corresponding terminal coalition structures and payoff vectors.

In the theory of characteristic function form games coalitions are 'orthogonal', that is, the value of a particular coalition can be given without reference to other coalitions. This makes the definition of the core (Shapley, 1955) especially simple and intuitive: given a particular allocation of the value of the grand coalition, each coalition compares its total payoff with its value and if it gets less than the latter it blocks the allocation: it threatens to leave cooperation. In partition function form games (Thrall and Lucas, 1963), where the value of a coalition depends on the entire coalition structure it is embedded in, the coalition does not in general know its payoff after a departure from the status quo and possibility of different coalition structures with the corresponding different coalitional payoffs are perceived by the players as uncertainty, too. In order to asses the consequences of a deviation, players form assumptions about the behaviour of the remaining players. The literature considers two types of assumptions: some specify the residual coalition structure explicitly, while others study the effect on the deviating coalitions. We briefly review these models.

Originally von Neumann and Morgenstern (1944) defined the characteristic function using the minimax rule: here the coalition assumes that the remaining players try to minimise its payoff. A similar idea is used by (Aumann and Peleg, 1960) when defining the $\alpha$-core. This conservative or prudent approach is a common approach in economics, but this pessimism should not extend to unreasonable reactions (Rosenthal, 1971) and already very mild restrictions have substantial effects on the core (Richter, 1974). This approach, however ignores the incentives of the residual players; Chander and Tulkens (1997) were the first to explicitly model in the $\gamma$-core best responses of residual players focussing on individual best responses corresponding to the specific residual coalition structure where all coalitions are singletons. The $\delta$-core of Hart and Kurz (1983) reflects exactly the opposite: remaining players form a single coalition. Kóczy (2007) and Huang and Sjöström (2003) generalised the idea of a rational response by allowing arbitrary equilibrium coalition structures to form - where the equilibrium is the same as the one applied to the original game. The resulting recursive core and $r$-core have thus a recursive definition. 
While these approaches often drastically reduce the number of residual coalition structures, Kóczy (2007) still considers optimistic and pessimistic versions depending on which residual core outcomes (and corresponding coalition structures) form. As a result, for the pessimistic recursive core, the risk of a slight loss cancels the prospect of a substantial improvement, and, correspondingly for the optimistic recursive core, the prospect of a slight improvement under some reaction distracts our attention from the substantial losses under other scenarios. Lekeas and Stamatopoulos (2011) considers oligopolistic markets and instead of looking at extreme cases, takes a probabilistic approach, where the coalition attaches probabilities to each possible residual partition and considers the expected payoff under these probabilities. They follow the logit quantal response model of McKelvey and Palfrey (1995) in assuming that the probability of the different residual partitions is proportional to their relative payoffs.

Our approach differs in at least two aspects. On the one hand the probabilities we attach to possible residual strategies will be more general and differently motivated. On the other hand we do not simply look at expected values, but look at the risk of the deviation. Our risk concept (see Krokhmal et al., 2011, for a recent survey) comes from the finance literature, where risk merely indicates the uncertainty of a value of an asset. Therefore we compare the deviation to a financial investment where the coalition "invests" its current payoffs into a risky asset whose realised value depends on the state of the world manifested by the residual partition. The value of this risky asset is measured by an appropriate risk measure. In a sense the coalition's prospects are evaluated taking both the residual players preferences or incentives and the coalition's conservativism into account.

The structure of the paper is then as follows. First we introduce the basic notions, the game form as well as risk and risk measures. We then introduce the risk-based core and show some properties. At last we present a wide range of further applications.

\section{Preliminaries}

\subsection{Characteristic function form games with uncertainty}

Let $N$ denote the set of players. Subsets are called coalitions. We consider games where the value of a coalition depends on the state of the world. Let $\mathcal{S}=\left\{s_{1}, \ldots, s_{i}, \ldots, s_{S}\right\}$ denote a finite set of states. Then a cooperative game with uncertainty is a tuple $(N, v, \mathcal{S}, p)$ where $v: 2^{N} \times \mathcal{S} \rightarrow \mathbb{R}$ is a state-dependent 
characteristic function and $p$ is a probability vector: the state of nature $s$ occurs with probability $p_{s} \geq 0$ and $\sum_{s=1}^{S} p_{s}=1$. For each coalition $C$, depending on the state $s$ of the world the realised payoff may be different. The vector $x=v(C) \in \mathbb{R}^{S}$ collecting these payoffs, is referred to as the realization vector.

Consider a set $X \subseteq \mathbb{R}^{S}$ of realization vectors. The vector $x \in X$ represents the coalition's possible payoff realizations depending on the state of the world. The amount $x_{s}$ is the portfolio's payoff in state of nature $s \in S$. The inequality $y \geq x$ means that $y_{s} \geq x_{s}$ for all $s=1, \ldots, S$. The discrete random variable generated by $p \in \mathbb{R}_{+}^{S}$ and $x \in X$ is denoted by $\hat{x}$.

\subsection{Risk}

In the following we give a general introduction of risk and risk measures translating it to our particular coalitional model. Our introduction and notation follows Csóka et al. (2007).

We see the deviation of a coalition as an investment into a risky asset: its own payoff after the residual players settled for a partition.

A measure of risk is a function $\rho: X \rightarrow \mathbb{R}$ measuring the risk of a portfolio from the perspective of the initial outcome. It is the minimal amount of cash the investor has to add to his portfolio, and to invest in a reference instrument today, such that it ensures that the risk involved in the portfolio is acceptable. The measure of risk can also be negative, meaning that a portfolio remains acceptable if a certain amount of cash is withdrawn from it. We assume that the reference instrument has payoff 1 in each state of nature at $t=1$, thus its realization vector is $\mathbf{1}=(1, \ldots, 1) \in X$. The reference instrument is riskless in the "classical sense", having no variability in its payoffs.

For the deviating coalition $C$ the measure $\rho_{C}(x)$ tells us how much (transferable) utility to add to make it equivalent to a zero initial payoff. When the risk measure is used to evaluate the deviation of coalition from the initial outcome $(z, \mathcal{P})$ the deviation is worthwhile if

$$
\sum_{i \in C} z_{i}<-\rho_{C}(x)
$$

The definition of coherent measures of risk can be adjusted to the discrete case as follows.

Definition 1 (Coherent measure of risk, Artzner et al., 1999). A function $\rho: V \rightarrow \mathbb{R}$ is a coherent measure of risk if it satisfies the following axioms.

1. Monotonicity: for all $x, y \in X$ such that $y \geq x$, we have $\rho(y) \leq \rho(x)$. 
2. Subadditivity: for all $x, y \in X$ such that $x+y \in X$, we have $\rho(x+y) \leq \rho(x)+\rho(y)$.

3. Positive homogeneity: for all $x \in X, h \in \mathbb{R}_{++}$such that $h x \in X$, we have $\rho(h x)=h \rho(x)$.

4. Translation invariance: for all $x \in X$ and $a \in \mathbb{R}$ such that $x+a \mathbf{1} \in X$, we have $\rho(x+a \mathbf{1})=\rho(x)-a$.

The axioms are motivated as follows.

By monotonicity if a portfolio $y$ is always worth at least as much as $x$ (event by event), then $y$ cannot be riskier than $x$.

Subadditivity says that if we combine two portfolios, the risk is not greater than the sum of the risks associated with each: it captures the notion of diversification. If an exchange's measure of risk would fail to satisfy this property, then a trader could be better off by splitting his position, opening two accounts and decreasing the margin requirements. The same motivation applies to firms, banks, insurance companies, etc. For instance, for the case of internal capital budgeting, if the measure of risk satisfies subadditivity, then the head office can be sure that by setting risk limits to the divisions, the risk of the whole firm will be smaller than the sum of the individual risk limits. This enables the head office to decentralize the risk constraints.

Positive homogeneity requires that portfolio size should linearly influence risk.

Translation invariance ensures that the measure of risk is expressed in appropriate units. It means that investing an amount $a>0$ (or $a<0$ ) of cash into $a$ units of reference instrument initially leads to the payoff vector $a \mathbf{1}$ at the end and decreases (respectively: increases) the measure of risk by $a$.

The four axioms above seem natural, but it is well known that the rather popular Value-at-Risk (VaR) is not subadditive and hence it is not a coherent measure of risk. As a byproduct checking the relevance of the coherency axioms from a general equilibrium perspective enables us to assess this attack on VaR as well.

Acerbi (2002) treats spectral measures of risk in case of discrete random variables with equiprobable outcomes, that is, when $p_{1}=\cdots=p_{S}=1 / S$, as a special case. He assumes that the domain is $\mathbb{R}^{S}$. In this paper we explicitly want to allow for states with different (some with 0) probability, so we use the slightly more general formulation of (Cotter and Dowd, 2006). Our model is a generalization also in the sense that we consider a general domain $X \subseteq \mathbb{R}^{S}$. 


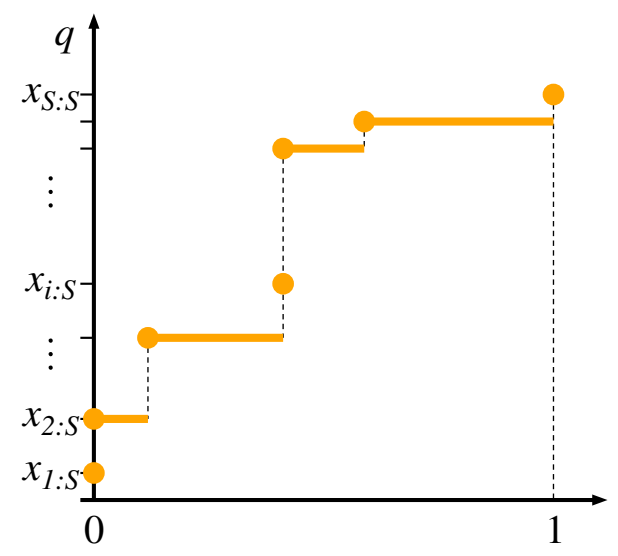

Figure 1: Quantile functions are monotone increasing, right continuous

Let us introduce the ordered statistics $x_{s: S}$ given by the ordered values of the $S$-tuple $x_{1}, \ldots, x_{S}$, i.e. $\left\{x_{1: S}, \ldots, x_{S: S}\right\}=\left\{x_{1}, \ldots, x_{S}\right\}$ and $x_{1: S} \leq x_{2: S} \leq \cdots \leq$ $x_{S: S}$. Let $q(p)$ denote the $p$-quantile over these order statistics. The quantile $q(p)$ as a function of $p$ is the inverse of the cumulative probability distribution and is monotonically increasing, right-continuous.

Definition 2. Consider the quantiles $q(p), p \in[0,1]$, and a function $\phi:[0,1] \rightarrow$ $\mathbb{R}^{S}$. The measure $M_{\phi}: X \rightarrow \mathbb{R}$ defined by

$$
M_{\phi}(x)=-\int_{0}^{1} \phi(p) q(p) d p
$$

is a spectral measure of risk if $\phi \in \mathbb{R}^{S}$ satisfies the conditions

1. Nonnegativity: $\phi(p) \geq 0$ for all $p \in[0,1]$,

2. Normalization: $\int_{0}^{1} \phi(p) d p=1$,

3. Monotonicity : $\phi$ is non-increasing, i.e. $\phi_{p_{1}} \geq \phi_{p_{2}}$ if $0 \leq p_{1}<p_{2} \leq 1$.

Spectral measures of risk are calculated as discounted weighted average losses, with weakly decreasing weights, with the highest weight on the worst outcome. The weight function $\phi$ is the so-called risk spectrum.

Here monotonicity really meant a non-increasing $\phi$ function. We will also consider anti-spectral risk measures, where the last condition is replaced by

3'. Anti-monotonicity : $\phi$ is non-decreasing, i.e. $\phi_{p_{1}} \leq \phi_{p_{2}}$ if $0 \leq p_{1}<p_{2} \leq 1$.

Note that in our model the risk measure takes on the same role as the more general preference relation used by Timmer et al. (2005). 


\section{The risk-based core}

In this section we introduce the risk-based core and discuss some of its properties.

Our interest lies in stable allocations of the coalitional payoffs. The triple $(a, \mathcal{P}, s)$ consisting of a state of the world $s$, a coalition structure $\mathcal{P}$ and an allocation vector $a \in \mathbb{R}^{N}$ such that $\sum_{i \in C} a_{i}=v(C, s)$ for all $C \in \mathcal{P}$ is a payoff configuration.

In order to define the core, we must first understand dominance. Consider a possible deviation by coalition $C$. The payoff of coalition $C$ depends on the realised state of the world $s$. The quantile $q^{C}(p)$ tells us that with probability $p$ coalition $C$ has a value of at least $q^{C}(p)$. The conservatism of coalition $C$ is expressed by the spectral weight function $\phi$. We assume that $\phi$ is common over all coalitions. The risk of the deviation is then given by

$$
M_{\phi}(C)=-\int_{0}^{1} \phi(p) q^{C}(p) d p .
$$

So this is how much cash is needed to make the deviation acceptable (that is, of worth 0). Coalition $C$ is interested in how much payoff it is going to get in (weighted) expected terms, so it is natural to consider the worth function $W_{\phi}(C)=-M_{\phi}(C)$ instead.

Definition 3 (Risk-based core). Consider a characteristic function form game with uncertainty $(N, v, \mathcal{S}, p)$. Then the risk-based core under the common spectral weight function $\phi$ or $\phi$-core of this game $C_{\phi}(N, v, \mathcal{S}, p)$ collects payoff configurations $(a, \mathcal{P}, s)$ such that $\sum_{i \in C} a_{i} \geq W_{\phi}(C)$ for all $C \subseteq N$.

Consider the following three-player example.

Example 4. The task at hand is the assembly of a new wardrobe. Since we have no experience, we do not know what to expect and the task may turn out to be tricky $(s=1)$, very tricky $(s=2)$, easy $(s=3)$ or so-so $(s=4)$. Since this is a product sold in massive quantities all over the world, we must assume that it is very likely easy (90\%), but with some chance it is tricky (5\%) or very tricky $(5 \%)$. If it is so-so we will do it and will call it easy ex post, so so-so has 0 probability.

When a group attempts to fix the wardrobe their success may depend on the difficulty level. For simplicity we assume that assembly is very tricky (or outright dangerous) when working alone, three men can easily do it, while for any pair the success depends on the difficulty level. Formally we have a (symmetric) 


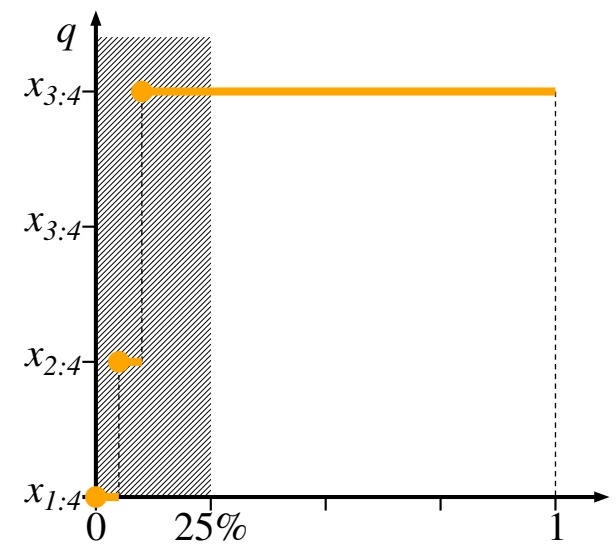

Figure 2: The example's quantile function. Under the 25\%-expected shortfall the expected value of the lowest $25 \%$ of cases is calculated

characteristic function $v$, such that $v(\{i\}, s)=0$ for all $i$ and $s, v(N, s)=3$ for all $s$ and

$$
v(\{i, j\}, s)= \begin{cases}1 & \text { if } s=1, \\ 0 & \text { if } s=2, \\ 3 & \text { if } s=3, \text { and } \\ 2 & \text { if } s=4,\end{cases}
$$

if $i, j \in N$ and $i \neq j$. Therefore the ordered statistics for this coalition can be given as $\left(x_{1: 4}, x_{2: 4}, x_{3: 4}, x_{4: 4}\right)=(0,1,2,3)$ with corresponding probabilities $(5 \%, 5 \%, 0 \%, 90 \%)$, which can also be given as the quantile function

$$
q^{\{i, j\}}(p)= \begin{cases}0 & \text { if } 0 \leq p<5 \% \\ 1 & \text { if } 5 \% \leq p<10 \%, \text { and } \\ 3 & \text { if } 10 \% \leq p \leq 100 \%\end{cases}
$$

We also assume that the players use a popular risk measure, the $\alpha$-expected shortfall ( $\alpha$-ES with $\alpha=25 \%$ ). For this measure

$$
\phi(p)= \begin{cases}4 & \text { if } 0 \leq p<25 \% \\ 0 & \text { otherwise }\end{cases}
$$

In effect the players calculate the expected value of the lowest $25 \%$ of the payoffs. The 25\%-expected shortfall of the 2-player coalitions is $W_{25 \% \text {-ES }}(\{i, j\})=4(0 \times$ $5 \%+1 \times 5 \%+3 \times 15 \%)=2$ for all $i \neq j \in N$. 
Then it is clear that $C_{25 \% \text {-ES }}(N, v, \mathcal{S}, p)=\{((1,1,1),\{N\}, s), \forall s \in \mathcal{S}\}$.

Notice that this core is very sensitive to the chosen spectral weight function. If the players use $\alpha$-expected shortfall with $\alpha>25 \%$, then $W_{\alpha \text {-ES }}(\{i, j\})>2$ and the core is empty. On the other hand, if $\alpha<25 \%$, that is, players are more conservative, $W_{\alpha \text {-ES }}(\{i, j\})<2$ and the core becomes larger.

This property is actually quite general as we show it in the next subsection.

\subsection{General results}

Before stating the following theorem, reconsider the risk spectrum function $\phi$. Apart from the additional (anti-)monotonicity criterion it can be seen as a probability density function. It is therefore appropriate to apply stochastic dominance to them.

Consider the probability density functions $\phi$ and $\psi$ with corresponding cumulative distribution functions $\Phi$ and $\Psi$. Then we say that $\phi$ first order stochastically dominates $\psi$ if

$$
\int_{0}^{x} \phi(p) d p>\int_{0}^{x} \psi(p) d p \quad \forall x .
$$

Theorem 5. Consider a characteristic function form game with uncertainty $(N, v, \mathcal{S}, p)$ and two spectral functions $\phi$ and $\psi$ such that $\phi(p)$ first order stochastically dominates $\psi(p)$, then $C_{\phi}(N, v, \mathcal{S}, p) \supseteq C_{\psi}(N, v, \mathcal{S}, p)$.

Proof. Assume the converse: Assume that there exists a payoff configuration $\left(a, \mathcal{P}, s_{0}\right)$ such that $\left(a, \mathcal{P}, s_{0}\right) \notin C_{\phi}(N, v, \mathcal{S}, p)$, but $\left(a, \mathcal{P}, s_{0}\right) \in C_{\psi}(N, v, \mathcal{S}, p)$. This is only possible if there exists a coalition $C$, such that $W_{\phi}(C)>\sum_{i \in C} a_{i}$, but $W_{\psi}(C) \leq \sum_{i \in C} a_{i}$. Equating the right hand side of the two inequalities and recalling Equation 2 we get

$$
\int_{0}^{1} \phi(p) q^{C}(p) d p>\int_{0}^{1} \psi(p) q^{C}(p) d p
$$

Recall that the deviation of $C$ could induce one of the finite possible states of the world corresponding to the different residual partitions. The coalitional payoffs $v(C, s)$ for each state $s$, together with the assigned probabilities $p_{s: S}$ to each $s$ of these - ordered - states determine a monotonically decreasing quantile 
function. Then

$$
\begin{aligned}
& \int_{0}^{1} \phi(p) q^{C}(p) d p=\int_{0}^{1} \phi(p) x_{S: S} d p+\int_{0}^{p_{S-1: S}} \phi(p)\left(x_{S-1: S}-x_{S: S}\right) d p+\ldots \\
&+\int_{0}^{p_{1: S}} \phi(p)\left(x_{1: S}-x_{2: S}\right) d p \\
&= x_{S: S} \int_{0}^{1} \phi(p) d p \\
&+\left(x_{S-1: S}-x_{S: S}\right) \int_{0}^{p_{S-1: S}} \phi(p) d p+\ldots \\
& \quad+\left(x_{1: S}-x_{2: S}\right) \int_{0}^{p_{1: S}} \phi(p) d p \\
& \leq x_{S: S} \int_{0}^{1} \psi(p) d p+\left(x_{S-1: S}-x_{S: S}\right) \int_{0}^{p_{S-1: S}} \psi(p) d p+\ldots \\
& \quad+\left(x_{1: S}-x_{2: S}\right) \int_{0}^{p_{1: S}} \psi(p) d p \\
&=\int_{0}^{1} \psi(p) q^{C}(p) d p
\end{aligned}
$$

where the inequality holds termwise by the repeated application of Inequality 3 and the fact that $x_{i: S}$ are monotone increasing in $i$ and therefore the differences $x_{i-1: S}-x_{i: S}$ are never positive.

This contradicts Inequality 4. Therefore our original assumption was false and the desired inclusion property holds.

While Theorem 5 compared cores of the same game, but under different behavioural assumptions, the following result compares games with different probability distributions - while keeping the players' interpretations the same.

Theorem 6. Consider a characteristic function form game with uncertainty $(N, v, \mathcal{S}, p)$ a spectral function $\phi$. Let also $q_{1}$ and $q_{2}$ denote two quantile functions such that $q_{1}(p) \geq q_{2}(p)$. Then $C_{q_{1}}(N, v, \mathcal{S}, p) \subseteq C_{q_{2}}(N, v, \mathcal{S}, p)$.

The proof is analogous to the proof of Theorem 5.

\subsection{Partition function form games}

In partition function form games (Thrall and Lucas, 1963; Kóczy, 2018) the value of a coalition depends on the entire partition of the players. Therefore the different partitions correspond to the different states of the world. In this section we formally define partition function games and present some special results. 
A partition $\mathcal{C}$ of coalition $C$ is a splitting of $C$ into disjoint coalitions. $\Pi(C)$ denotes the set of partitions of $C$. In general, we use capital and calligraphic letters to denote a set and its partition (the set of players $N$ being an exception), indexed capital letters are elements of the partition. We write $i \in \mathcal{C}$ if there exists $C_{k}$ such that $i \in C_{k} \in \mathcal{C}$ and if $i \in \mathcal{C}$ we write $\mathcal{C}(i)$ for the coalition embedded in $\mathcal{C}$ containing $i$. An embedded coalition is a pair $(C, \mathcal{P})$, where $C \in \mathcal{P}$. The set of embedded coalitions is denoted by $\mathcal{E}$.

A game in partition function form is a pair $(N, V)$, where $V: \mathcal{E} \rightarrow \mathbb{R}$ is the partition function, which assigns a real payoff to each embedded coalition, where $V\left(C_{i}, \mathcal{C}\right)$ denotes the payoff for coalition $C_{i}$ embedded in partition $\mathcal{C}$. For vectors $a, b \in \mathbb{R}^{N}$ we write $a_{C}$ for the restriction to the set $C$ and $a_{C}>b_{C}$ if $a_{i} \geq b_{i}$ for all $i \in C \subset N$ and there exists $j \in C$ such that $a_{j}>b_{j}$.

In this setting the state of the world is manifested by the emerging partition, which leads to a simpler concept of payoff configuration: The pair $\omega=(a, \mathcal{P})$ consisting of a payoff vector $a \in \mathbb{R}^{N}$ and a partition $\mathcal{P} \in \Pi(N)$ is a payoff configuration (or outcome) if $\sum_{i \in S} a_{i}=V\left(P_{i}, \mathcal{P}\right)$ for all $P_{i} \in \mathcal{P}$. The set of outcomes of game $(N, V)$ is denoted $\Omega(N, V)$.

The payoff of coalition $C$ depends on the partition formed in the residual game induced by the deviation of $C$ is $\left(\bar{C}, V^{\{C\}}\right)$. We follow Lekeas and Stamatopoulos (2011) in assuming that coalition $C$ cannot solve this game, it does not know how will the residual players react so it uses heuristics to assess the probabilities $p_{\overline{\mathcal{C}}}$ of the different residual partitions in $\overline{\mathcal{C}} \in \Pi(\bar{C})$ such that $\sum_{\overline{\mathcal{C}} \in \Pi(\bar{C})} p_{\overline{\mathcal{C}}}=1$. The coalition then sees the formation of the residual partitions as a random process where the different possible partitions emerge as different states of the world. The quantile $q^{C}(p)$ tells us that with probability $p$ coalition $C$ has a value of at least $q^{C}(p)$. There is a natural correspondence between partition function form games augmented with these probabilities and characteristic function form games with uncertainty: $(N, V, p) \sim(N, v, \mathcal{S}, p)$, where $\mathcal{S}=\Pi$ and $v(C, s)=V(C, s)$, where $s \in \mathcal{S}=\Pi$. Therefore, for convenience we continue using partition function form games. In particular, we redefine the risk-based core as simple risk-based core for partition function form games.

Definition 7 (Simple risk-based core). Consider a partition function form game $(N, V)$ where players have a common spectral weight function $\phi$. Then the simple risk-based core or $\phi$-core of this game $C_{\phi}(N, V)$ collects payoff configurations $(a, \mathcal{P})$ such that $\sum_{i \in C} a_{i} \geq W_{\phi}(C)$ for all $C \subseteq N$.

First we define the residual game over the set $R \subsetneq N$. $\Pi(S)$ denotes the set of partitions of $S$. Assume $\bar{R}=N \backslash R$ have formed $\overline{\mathcal{P}_{R}} \in \Pi(\bar{R})$. Then the 
residual game $\left(R, V_{\mathcal{P}_{\bar{R}}}\right)$ is the partition function form game over the player set $R$ with the partition function given by $V_{\mathcal{P}_{\bar{R}}}\left(C, \mathcal{P}_{R}\right)=V\left(C, \mathcal{P}_{R} \cup \mathcal{P}_{\bar{R}}\right)$.

Definition 8 (Optimistic/Pessimistic Recursive Core (Kóczy, 2007)). For a single-player game the recursive core is trivially defined. Now assume that the optmistic/pessimistic recursive core $C_{+}(N, V) / C_{-}(N, V)$ has been defined for all games with $|N|<k$ players. Then for an $|N|$-player game an outcome $(a, \mathcal{P})$ is optimistically dominated if there exists a coalition $Q$ forming partition $\mathcal{Q}$ and an outcome $\left(b, \mathcal{Q} \cup \mathcal{P}_{\bar{Q}}\right) \in \Omega(N, V)$, such that $b_{Q}>a_{Q}$ and if $C_{+}\left(\bar{Q}, V_{\mathcal{Q}}\right) \neq \varnothing$ then $\left(y_{\bar{Q}}, \mathcal{P}_{\bar{Q}}\right) \in C_{+}\left(\bar{Q}, V_{\mathcal{Q}}\right)$. It is pessimistically dominated if there exists a coalition $Q$ forming partition $\mathcal{Q}$ and a feasible payoff vector $b_{Q} \in \mathbb{R}^{Q}$, such that for all $\left(b_{Q}, b_{\bar{Q}}, \mathcal{Q} \cup \mathcal{P}_{\bar{Q}}\right) \in \Omega(N, V)$ we have $b_{Q}>a_{Q}$ and if $C_{-}\left(\bar{Q}, V_{\mathcal{Q}}\right) \neq \varnothing$ then $\left(b_{\bar{Q}}, \mathcal{P}_{\bar{Q}}\right) \in C_{-}\left(\bar{Q}, V_{\mathcal{Q}}\right)$. The optimistic/pessimistic recursive core $C_{+}(N, V) / C_{-}(N, V)$ of $(N, V)$ is the set of optimistically/pessimistically undominated outcomes.

The recursive cores are well-defined, though they may be empty.

Huang and Sjöström's (2003) r-core coincides with the pessimistic recursive core on a broad class of games that does not, however include the standard TU-games without externalities. Ray's (2007) standard equilibrium, defined for for symmetric partition function form games has a similar recursive structure. For an interpretation and the discussion of the properties of the recursive core see Kóczy (2007, 2009); Huang and Sjöström (2010). Kóczy (2018) gives a comprehensive overview of partition function form games including solutions and applications.

Consider an initial payoff-configuration $(a, \mathcal{P})$. When a coalition $C$ deviates, its deviation induces a new partition function form game. The definition of the residual game (Kóczy, 2007) is more general than what we need here:

Definition 9 (Residual game). Consider a partition function form game $(N, V)$. Let $R \subset N$ and $\overline{\mathcal{P}_{R}} \in \Pi(\bar{R})$ be the partition of $\bar{R}=N \backslash R$. Then the residual game $\left(R, V^{\overline{\mathcal{P}_{R}}}\right)$ is the partition function game played over player set $R$ such that $V^{\overline{\mathcal{P}_{R}}}\left(C, \mathcal{P}_{R}\right)=V\left(C, \mathcal{P}_{R} \cup \overline{\mathcal{P}_{R}}\right)$ for all $C \subseteq R$ and $\mathcal{P}_{R} \in \Pi(R)$.

Our model generalises various approaches where there are assumptions on either the probabilities of the residual coalition structures, or on the treatment of different prospects from the coalition's point of view. Acerbi (2002) assumes that the partitions are equiprobable, Lekeas and Stamatopoulos (2011) assume that their probability is proportional to their payoffs, von Neumann and Morgenstern (1944); Hart and Kurz (1983); Chander and Tulkens $(1995,1997)$ apply 
the disintegration or $\gamma$ - rule and effectively give probability 1 to the partition into singletons, while Maskin (2003) and McQuillin (2009) assume the grand coalition forms. Hart and Kurz (1983) introduced the $\delta$ - or projection rule, where the partition of the residual players remains unchanged after the departure of the deviating coalition, that is, those who belonged to the same coalition still do, and those who belonged to different coalitions, still do. The latter rule is axiomatically confirmed by Bloch and van den Nouweland (2014). On the other hand the $\alpha$-rule of Aumann and Peleg (1960) or the optimistic rule of Shenoy (1979) do not make assumptions about probabilities but rather specify attitudes to payoff levels: the players only care about the lowest or highest attainable payoff. At last, the recursive core (Kóczy, 2007) combines the two aspects as it rules out some residual partitions (in case they do not belong to a nonempty residual core), but at the same time uses optimism/pessimism to form expectations. The following proposition is constructive, does not require a proof.

Proposition 10. Consider a partition function form game $(N, V)$. The following core concepts can be established as risk-based cores with the appropriate probability mass functions $p$ and risk functions $\phi$ :

- The $\alpha$-core: $C_{\alpha}(N, V)=\lim _{\varepsilon \rightarrow 0} C_{\phi_{\varepsilon}}(N, V)$ where $p>0$ and

$$
\phi_{\alpha}^{\varepsilon}(p)= \begin{cases}\frac{1}{\varepsilon} & \text { if } 0 \leq p \leq \varepsilon \\ 0 & \text { otherwise }\end{cases}
$$

- The optimistic core: $C_{\omega}(N, V)=\lim _{\varepsilon \rightarrow 0} C_{\phi_{\varepsilon}}(N, V)$ where $p>0$ and

$$
\phi_{\omega}^{\varepsilon}(p)= \begin{cases}0 & \text { if } 0 \leq p \leq 1-\varepsilon \\ \frac{1}{\varepsilon} & \text { otherwise }\end{cases}
$$

- The $\gamma$-core: $C_{\gamma}(N, V)=C_{1}(N, V)$ with $\phi(p)=1$ and

$$
p^{C}(\mathcal{P})= \begin{cases}1 & \text { if } \mathcal{P}=\{\{i\} \mid i \in \bar{C}\} \\ 0 & \text { otherwise }\end{cases}
$$

- The cohesion-core: $C_{c}(N, V)=C_{1}(N, V)$ with $\phi(p)=1$ and

$$
p^{C}(\mathcal{P})= \begin{cases}1 & \text { if } \mathcal{P}=\{\bar{C}\} \\ 0 & \text { otherwise. }\end{cases}
$$


- Payoff proportional weights: $C_{p p}(N, V)=C_{1}(N, V)$ with

$$
p^{C}(\mathcal{P})=\frac{V(C,\{C\} \cup \mathcal{P})}{\sum_{\mathcal{Q} \in \Pi(\bar{C})} V(C,\{C\} \cup \mathcal{Q})},
$$

- The pessimistic simple recursive core: $R C_{\alpha}(N, V)=\lim _{\varepsilon \rightarrow 0} C_{\phi_{\alpha}^{\varepsilon}}(N, V)$ with the spectral function $\phi_{\alpha}^{\varepsilon}$ from Equation 9 and probability mass function

$$
p^{C}(\mathcal{P})= \begin{cases}\frac{1}{c} & \text { if } R C_{\alpha}\left(\bar{C}, V^{\{C\}}\right) \neq \varnothing \text { and } \exists a:(a, \mathcal{P}) \in R C_{\alpha}\left(\bar{C}, V^{\{C\}}\right) \\ 0 \quad \text { otherwise, }\end{cases}
$$

where $c$ is the number of partitions $\mathcal{P}$ such that $\exists a:(a, \mathcal{P})_{\alpha} \in R C\left(\bar{C}, V^{\{C\}}\right)$.

- The optimistic simple recursive core: $R C_{\omega}(N, V)=\lim _{\varepsilon \rightarrow 0} C_{\phi_{\omega}^{\varepsilon}}(N, V)$ with the spectral function $\phi_{\omega}^{\varepsilon}$ from Equation 10 and probability mass function

$$
p^{C}(\mathcal{P})= \begin{cases}\frac{1}{c} & \text { if } R C_{\omega}\left(\bar{C}, V^{\{C\}}\right) \neq \varnothing \text { and } \exists x:(a, \mathcal{P}) \in R C_{\omega}\left(\bar{C}, V^{\{C\}}\right) \\ 0 \quad \text { otherwise, }\end{cases}
$$

where $c$ is the number of partitions $\mathcal{P}$ such that $\exists a:(a, \mathcal{P}) \in R C_{\omega}\left(\bar{C}, V^{\{C\}}\right)$.

For the projection core the probabilities depend on the initial partition and therefore cannot be presented in this form.

Theorem 5 provides an alternative proof to the following inclusion relations, originally presented by Kóczy (2007).

Corollary 11. Consider a partition function form game $(N, V)$. Then the following results hold:

- $C_{\omega}(N, V) \subseteq C_{\alpha}(N, V)$

- $C_{\gamma}(N, V) \subseteq C_{\alpha}(N, V)$

- $C_{c}(N, V) \subseteq C_{\alpha}(N, V)$

- $C_{p p}(N, V) \subseteq C_{\alpha}(N, V)$

Proof. The first follows directly from Theorem 5. The second, third and fourth condition compares a pessimistic approach where the focus is on the function $\phi$ and the only restriction on $p$ is to ensure that partition with the lowest coalitional payoff has a positive weight, and approaches with explicitly given residual partitions. Such models with exogenously given residual behaviour are 
based on the assumption that the specified partition forms with certainty so the probability of all other partitions is 0 . To make the two situations compatible we consider a limiting process where we allow very small probabilities to all other partitions, too, prove the relation for this perturbed game and consider the limit.

It is natural to ask whether similar inclusion properties, such as $R C_{\omega}(N, V) \subseteq$ $R C_{\alpha}(N, V)$ or $R C_{\alpha}(N, V) \subseteq C_{\alpha}(N, V)$ could be shown analogously. For the latter the risk measures are the same, the difference lies in the probability mass functions. Unfortunately for the recursive core inclusions the conditions of Theorem 6 do not hold in general. To see this note that the quantile functions are decreasing step functions where the steps correspond to the different residual partitions. When these partitions are restricted to residual core partitions, some of these steps are removed. The extrema of the quantile function do not change producing the desired relation. On the other hand this result is not robust: for the slightest perturbation of the spectral function there is an example for which the inclusion relation is violated.

\section{Discussion}

The risk based core allows for a very general stability concept for coalitional games with uncertainty, and in particular for partition function form games, where both the perceived probability of residual reactions and the conservativism of the players can be set independently. We have shown how the known core concepts emerge as (very) special cases and proved properties for the inclusion relations of cores with different probability mass functions and especially with different spectral functions.

What remains to be seen is where the probabilities of the different partitions come from. Kóczy (2018) describes an alternative formulation of the recursive core with a dynamic residual game. A dynamic, myopic process is either absorbed in a residual core outcome or goes on indefinitely. Modelled as a Markovian process we can naturally consider its invariant distribution.

While our interest is primarily theoretical, one cannot overlook the computational advantages of these methods. Calculating the recursive core is a computationally very intensive task already for problems with a handful of players. Modelling the dynamic process above it is possible to approximate the probability mass functions in the residual games, allowing for a quicker calculation. 


\section{Acknowledgements}

The author thanks the extensive comments of Zsolt Bihary and Dóra Petróczy, which greatly improved the paper. This research was supported by the Higher Education Institutional Excellence Program of the Ministry of Human Capacities in the framework of the 'Financial and Public Services' research project (1783-3/2018/FEKUTSTRAT and 20764-3/2018/FEKUTSTRAT) at Corvinus University of Budapest.

\section{References}

Acerbi, C., 2002, Spectral measures of risk: A coherent representation of subjective risk aversion, Journal of Banking \& Finance 26, 1505-1518.

Artzner, P., F. Delbaen, J. Eber, and D. Heath, 1999, Coherent measures of risk, Mathematical Finance 9, 203-228.

Aumann, R. J. and B. Peleg, 1960, Von Neumann-Morgenstern solutions to cooperative games without side payments, Bulletin of the American Mathematical Society 66, 173-179.

Bloch, F. and A. van den Nouweland, 2014, Expectation formation rules and the core of partition function, Games and Economic Behavior 88, 339-353.

Bossert, W., J. Derks, and H. Peters, 2005, Efficiency in uncertain cooperative games, Mathematical Social Sciences 50, 12-23.

Chander, P. and H. Tulkens, 1995, A core-theoretic solution for the design of cooperative agreements on transfrontier pollution, International Tax and Public Finance 2, 279-293.

Chander, P. and H. Tulkens, 1997, The core of an economy with multilateral environmental externalities, International Journal of Game Theory 26, 379401.

Charnes, A. and D. Granot, 1973, Prior solutions: Extensions of convex nucleus solutions to chance-constrained games, in: Computer Science and Statistics, vol. 7 (Iowa State University), 323-332.

Charnes, A. and D. Granot, 1976, Coalitional and chance-constrained solutions to n-person games. I: The prior staisficing nucleolus, SIAM Journal on Applied Mathematics 31, 358-367. 
Cotter, J. and K. Dowd, 2006, Extreme spectral risk measures: An application to futures clearinghouse margin requirements, Journal of Banking \& Finance 30, 3469-3485.

Csóka, P., P. J.-J. Herings, and L. Á. Kóczy, 2007, Coherent measures of risk from a general equilibrium perspective, Journal of Banking Finance 31, 25172534 .

Granot, D., 1977, Cooperative Games in Stochastic Characteristic Function Form, Management Science 23, 621-630.

Habis, H. and D. Csercsik, 2015, Cooperation with externalities and uncertainty, Networks and Spatial Economics 15, 1-16.

Habis, H. and P. J.-J. Herings, 2010, A note on the weak sequential core of dynamic TU games, International Game Theory Review 12, 407-416.

Habis, H. and P. J.-J. Herings, 2011, Transferable utility games with uncertainty, Journal of Economic Theory 146, 2126-2139.

Hart, S. and M. Kurz, 1983, Endogenous formation of coalitions, Econometrica $51,1047-1064$.

Huang, C.-Y. and T. Sjöström, 2003, Consistent solutions for cooperative games with externalities, Games and Economic Behavior 43, 196-213.

Huang, C.-Y. and T. Sjöström, 2010, The recursive core for non-superadditive games, Games 1, 66-88.

Kóczy, L. Á., 2002, Finding the best way to join in: A dynamic accession game, in: S. Parsons, P. Gmytrasiewicz, and M. Wooldridge, eds., Game Theory and Decision Theory in Agent-Based Systems, vol. 5 of Multiagent Systems, Artificial Societies, and Simulated Organizations, chap. 8 (Kluwer Academic Publishers), 159-176.

Kóczy, L. Á., 2007, A recursive core for partition function form games, Theory and Decision 63, 41-51.

Kóczy, L. Á., 2009, Sequential coalition formation and the core in the presence of externalities, Games and Economic Behavior 66, 559-565.

Kóczy, L. Á., 2018, Partition function form games, Theory and Decision Library C 48 (Springer International Publishing). 
Konishi, H. and D. Ray, 2003, Coalition formation as a dynamic process, Journal of Economic Theory 110, 1-41.

Koutsougeras, L. C., 1998, A two-stage core with applications to asset market and differential information economies, Economic Theory 11, 563-584.

Krokhmal, P., M. Zabarankin, and S. Uryasev, 2011, Modeling and optimization of risk, Surveys in Operations Research and Management Science 16, 49-66.

Lekeas, P. V. and G. Stamatopoulos, 2011, Cooperative oligopoly games: a probabilistic approach, arXiv 1107, 1-10.

Maskin, E., 2003, Bargaining, coalitions and externalities.

McKelvey, R. and T. R. Palfrey, 1995, Quantal response equilibria for normal form games, Games and economic behavior 10, 6-38.

McQuillin, B., 2009, The extended and generalized Shapley value: Simultaneous consideration of coalitional externalities and coalitional structure, Journal of Economic Theory 144, 696-721.

von Neumann, J. and O. Morgenstern, 1944, Theory of games and economic behavior (Princeton University Press, Princeton).

Predtetchinski, A., 2007, The strong sequential core for stationary cooperative games, Games and Economic Behavior 61, 50-66.

Predtetchinski, A., P. J.-J. Herings, and H. Peters, 2002, The strong sequential core for two-period economies, Journal of Mathematical Economics 38, 465482 .

Ray, D., 2007, A Game-Theoretic Perspective on Coalition Formation (Oxford University Press, Oxford).

Richter, D. K., 1974, The core of a public goods economy, International Economic Review 15, 131-142.

Rosenthal, R. W., 1971, External economies and cores, Journal of Economic Theory $3,182-188$.

Shapley, L. S., 1955, Markets as cooperative games, Tech. rep., The Rand Corporation.

Shenoy, P. P., 1979, On coalition formation: A game-theoretical approach, International Journal of Game Theory 8, 133-164. 
Suijs, J., P. Borm, A. De Waegenaere, and S. Tijs, 1999, Cooperative games with stochastic payoffs, European Journal of Operational Research 113, 193-205.

Suijs, J., A. De Waegenaere, and P. Borm, 1998, Stochastic cooperative games in insurance, Insurance: Mathematics and Economics 22, 209-228.

Thrall, R. M. and W. F. Lucas, 1963, N-person games in partition function form, Naval Research Logistics Quarterly 10, 281-298.

Timmer, J., P. Borm, and S. Tijs, 2005, Convexity in stochastic cooperative situations, International Game Theory Review 7, 25-42. 